Ethiopian Journal of Environmental Studies \& Management 8(3): 301 - 307, 2015.

ISSN:1998-0507

doi: http://dx.doi.org/10.4314/ejesm.v8i3.7

Submitted: January 22, 2015

Accepted: March 30, 2015

\title{
CORRELATING ANNUAL PICHE EVAPORATION OVER SUDAN AND SOUTH SUDAN TO LATITUDES, LONGITUDES AND ALTITUDES
}

MOHAMED, H.A.

National Institute of Desert Studies, University of Gezira, Wad Medani, Sudan

Email: habiballa1954@yahoo.com

\begin{abstract}
Piche evaporation in $\mathrm{mm} /$ day for Sudan and South Sudan for the period 1961- 1990 was obtained as normal data for 42 stations, and analyzed for correlations between evaporation on the one hand and latitudes, longitudes and elevations on the other hand. Excel statistical package was used for analysis. Data was analyzed for the whole of Sudan and South Sudan. For the 42 stations, evaporation increased on average with increase in latitudes at a rate of about $0.67 \mathrm{~mm} /$ degree showing a highly significant linear correlation ( $P=4.95 E-07)$. When the 5 Red Sea stations were removed, analysis for the 37 stations resulted in higher significance $(P=4.61 E-14)$, and evaporation increased at a rate of about $0.98 \mathrm{~mm} /$ degree latitude. When 5 South Sudan stations were removed, the increase in evaporation per degree latitude for the 32 stations was $0.96 \mathrm{~mm} /$ degree, almost similar to that for the 37 stations. Analysis for longitudes using 42 stations showed week or no significant correlation with evaporation, but demonstrated three clear localized patterns two of which showed a strong correlation between evaporation and longitudes; a South Sudan almost flat trend, a western Sudan moderate slope trend where evaporation decreased at about $0.52 \mathrm{~mm} /$ degree longitude east and a general steep slope trend where evaporation decreased at a rate of about $1.1 \mathrm{~mm} /$ degree longitude. Using 32 stations for Sudan, longitudes showed once again the two different evaporation patterns; the western Sudan trend with almost the same slope and the general steep slope trend with also similar slope. Altitudes on the other hand showed no clear correlation to evaporation when all the 42 stations were considered. When the South Sudan and Red Sea stations were removed, the remaining 32 stations showed significant $(P=0.01)$ correlation with evaporation which declined at a rate of about 0.01 $\mathrm{mm} / \mathrm{meter}$ above sea level.
\end{abstract}

Key Words: Piche evaporation, Latitude, Longitude, Altitude, Sudan

\section{Introduction}

Sudan, and South Sudan (SS) with their hyper-arid, arid, semi-arid, sub humid and humid climates experience high temperatures, (Mohamed, 2012), a high amount of solar radiation and a high rate of evaporation throughout the year, (Oliver, 1965). According to Shaltout and El
Housry (1997), the high evaporation rate from Lake Nasser constitutes one of the national problems in Egypt. These dry environments result in high atmospheric demand for water vapour, high evaporation rates and high crop water requirements. High irrigation cost constitutes an obstacle for agricultural production in the tropical 
arid. High cost of water pumping and delivery is a major limiting factor for irrigation by small resource-poor farmer, (Pasternak et al, 2010). Although rain fed agriculture in Sudan constitutes an important sector that supplies the country with grains, irrigated agriculture remains vital for the countrys food security. Almost all the irrigated areas in Sudan fall in arid and the semi arid zones of the country. The major item that may jeopardize the agricultural yield in Sudan is probably irrigation. Knowledge of the magnitude and variation of evaporative losses is required in water resource planning and management and in water supply requirements of irrigation projects, (Xu and Singh, 2001).Reliable estimation of evapotranspiration is essential to water resources planning and management, (Trajkovic and Gocic,2010).Evaporative demand can be determined by application of any of various equations developed for this purpose or more simply can be estimated from direct measurements using standard evaporimeter. Correct evaporation measurements and /or predictions are essential for calculation of exact crop water requirement, particularly in a vast country with varying climates like Sudan, (Fayed, 1966). Gasm Elseed,(1968) reported a decrease of evaporation in Sudan with a decrease in latitude, which may indicate a correlation between evaporation and latitudes. Evaporation measurements using Piche evaporimeter results in a rather high evaporation values on absolute basis, but it is still quite useful because of its simplicity and wide coverage. It is especially useful when comparing evaporation in various geographic locations and can be easily adjusted to other measuring systems as required. However, as a problem, the net work of such instruments may not cover an area of a vast country like Sudan. Since the Sudan can be viewed as one vast plain broken only by the Marra and Nuba mountains and few other topographical features, (Ireland, 1948) and because of the evidences of an increasing evaporation from south northward of Sudan, it is suggested that there is a strong correlation between evaporation and latitudes. The objective of the current study is to prove that linkage and to develop equations for the assessment of evaporation over Sudan and SS especially in areas where no records are available. This to be achieved though investigation of possible correlation between Piche evaporation over Sudan and SS on one hand and latitudes, longitudes and altitudes on the other hand.

\section{Study Area}

The coordinates and elevations of the stations were obtained mainly from Sudan Meteorological Authority (SMA). Table1 shows the latitudes in degrees north $(\mathrm{N})$, longitudes in degrees east (E), and altitudes in meters above sea level (MASL) of the various stations. The stations were grouped according to their geographic locations as 42 in Sudan and SS, 37 in Sudan and SS but with no 5 Red Sea (RS) stations and 32 in Sudan with no 5 SS or 5 RS coastal or nearby area stations. 
Table 1: Latitudes, Longitudes and Altitudes of the 42 stations in Sudan and SS

\begin{tabular}{|c|c|c|c|c|c|c|c|}
\hline Station & Latitude & longitude & Altitude & Station & Latitude & Longitude & Altitude \\
\hline Wadi halfa & 21.82 & 31.35 & 190 & Portsudan & 19.58 & 37.22 & 002 \\
No.6 & 20.75 & 32.55 & 470 & Toker & 18.43 & 37.73 & 020 \\
Abu hamad & 19.53 & 33.33 & 315 & Aqiq & 18.23 & 38.18 & 002 \\
Dongola & 19.17 & 30.48 & 228 & Kassala & 15.47 & 36.40 & 500 \\
Karima & 18.55 & 31.85 & 249 & Aroma & 15.85 & 36.15 & 431 \\
Atbara & 17.70 & 33.97 & 345 & Halfaelga. & 15.32 & 35.60 & 451 \\
Hudeiba & 17.57 & 33.93 & 350 & Showak & 14.40 & 35.85 & 510 \\
Shendi & 16.70 & 33.43 & 360 & Elfasher & 13.63 & 25.33 & 730 \\
Khartoum & 15.60 & 32.55 & 380 & Geneina & 13.45 & 22.45 & 805 \\
Shambat & 15.67 & 32.53 & 380 & Elobied & 13.17 & 30.23 & 574 \\
Eddueim & 14.00 & 32.33 & 378 & Gedaref & 14.03 & 35.40 & 599 \\
Wadmedani & 14.38 & 33.48 & 405 & Umbenain & 13.07 & 33.95 & 435 \\
Sennar & 13.55 & 33.62 & 418 & Ennuhood & 12.70 & 28.43 & 565 \\
Kosti & 13.17 & 32.73 & 380 & Nyala & 12.05 & 24.88 & 674 \\
Damazine & 11.78 & 34.38 & 470 & Abunaama & 12.73 & 34.13 & 445 \\
Malakal & 09.55 & 31.65 & 390 & Renk & 11.75 & 32.78 & 282 \\
Rumbek & 06.80 & 29.70 & 420 & Rashad & 11.87 & 31.05 & 885 \\
Juba & 04.87 & 31.60 & 457 & Babanusa & 11.33 & 27.80 & 450 \\
Gazala & 11.47 & 26.28 & 485 & Kadugli & 11.00 & 29.72 & 499 \\
Arbaat & 19.83 & 36.97 & 120 & Raga & 08.47 & 25.68 & 545 \\
Halaieb & 22.22 & 36.65 & 002 & Waw & 07.70 & 28.02 & 435 \\
\hline
\end{tabular}

\section{Methodology}

Piche evaporation data on daily basis for Sudan and South Sudan were obtained as monthly and yearly normal values for the period 1961-1990 and for 42 meteorological stations. The data was analyzed using excel statistical package for correlations between daily Piche evaporation data on the one hand and either of latitudes, longitudes, altitudes or their combinations on the other hand. In addition, the average maxima and minima daily Piche evaporation across stations and months were determined.

\section{Result and Discussion}

\section{Evaporation and Latitudes}

Figure 1 shows the correlation between Piche evaporation in $\mathrm{mm} /$ day and latitudes for 42 stations in Sudan and South Sudan.

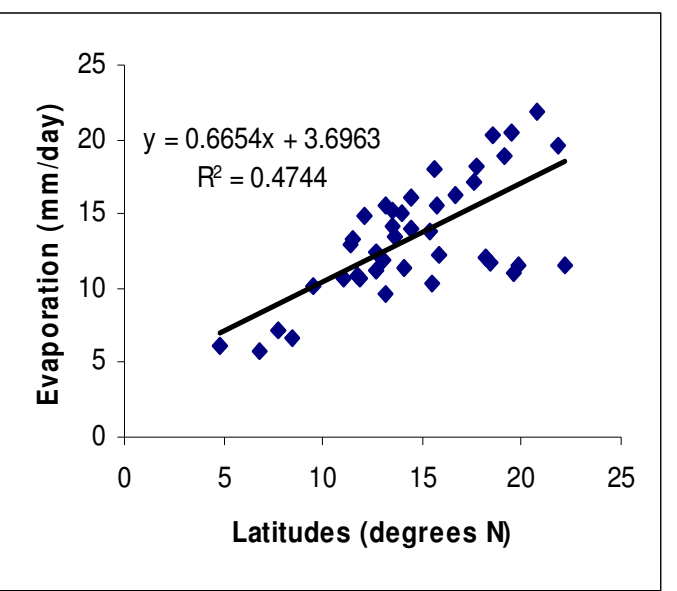

Figure1: Piche evaporation vs. latitudes for 42 stations

The trend is linear with a correlation coefficient $(\mathrm{R})$ of 0.69 , standard error (SE) of 2.8 and a significance of $4.59 E-07$. 
Evaporation increased from south to north with latitudes at a rate of about 0.67 $\mathrm{mm} /$ degree $\mathrm{N}$. In fact, figure1 shows clearly two trends rather than one; a trend with even a higher linearity, higher correlation $(\mathrm{R}=0.89)$, higher significance $(\mathrm{P}=4.61 E-14)$ and a lower standard error (1.8) as can be seen in figure 2 and another trend that is more or less flat. This rather flat trend is represented by the deviating points in figure 1 and is mainly the 5 coastal RS stations. This is because of their geographic location that keeps evaporation rather low.

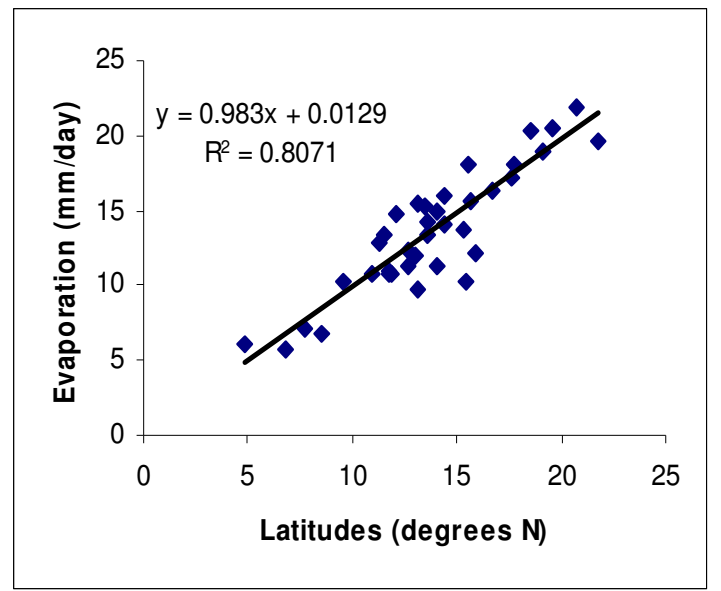

Figure 2: Piche evaporation vs. latitudes for 37 stations in Sudan and SS

Evaporation in fig.2 increased with latitude at a rate of about $0.98 \mathrm{~mm} /$ degree from south to north and because the figure displayed a higher linearity and showed a lower SE, an equation can be formulated to predict Piche evaporation (PE) from latitudes (Lat.) in areas where no measurements are available;

$\mathrm{PE}=0.98$ Lat. +0.01

The equation holds true almost all over the country with exception of RS coastal area and the nearby interior to about longitude 36 east. This result confirms the finding of (Gasm Elseed, 1968) that evaporation decreases from north to south and that evaporation isolines seem to run roughly a long the latitudes. Although similar correlations were developed between rainfall, latitudes and other factors, (Diskin, 1970; Nicholls and Wong,1990), it seems to be no such similar studies were conducted regarding evaporation.

\section{Evaporation and longitudes}

Figure 3 shows no correlation between evaporation and longitudes when all the 42 stations were considered. However, the figure clearly demonstrates three distinct patterns; a flat or low slope, low evaporation trend represented by 4 of the SS stations (Raja, Wau, Rumbek and Juba), a moderate slope trend represented mainly by western Sudan stations, (Genaina, Nyala, Fasher, Gazala , Babanusa, Nuhood, Kadugli, Rashad in addition to Renk, Malakal and Kosti), and a general steep slope trend represented by the rest of the stations.

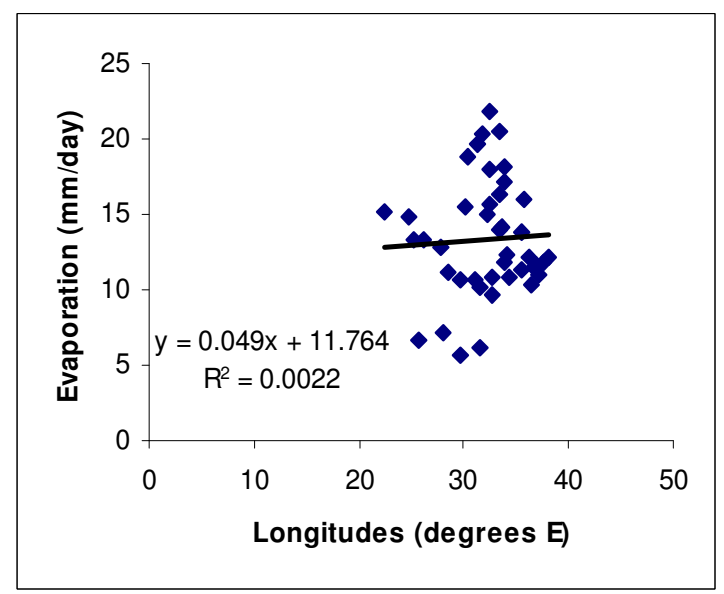

Figure 3: Piche evaporation vs. longitudes for the 42 stations

Figure 4 shows the plot of evaporation vs. longitudes for the 11 mainly western Sudan stations. The correlation is highly linear $(\mathrm{R}=0.94)$, with a very high significance, $(\mathrm{P}=8.36 E-06)$ and a low standard error, (0.6).Evaporation decreased as longitudes increased eastward at a rate of about $0.5 \mathrm{~mm} /$ degree longitude. 


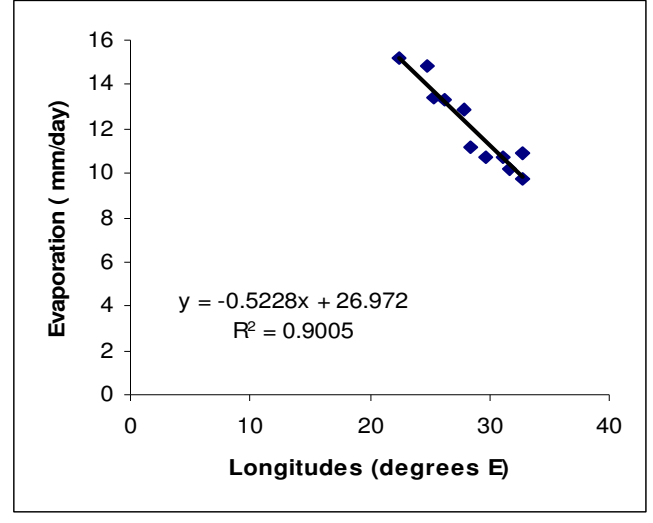

Figure 4: Piche evaporation vs. longitudes for the 11 stations

For the rest of the stations (27 stations) fig.5 shows a linear correlation, with high significance $(\mathrm{P}=3.42 E-05)$ and $\mathrm{a}$ moderate $\mathrm{R}$ of 0.71 . Evaporation decreased as longitudes increased at a rate of about $1.1 \mathrm{~mm} /$ degree.

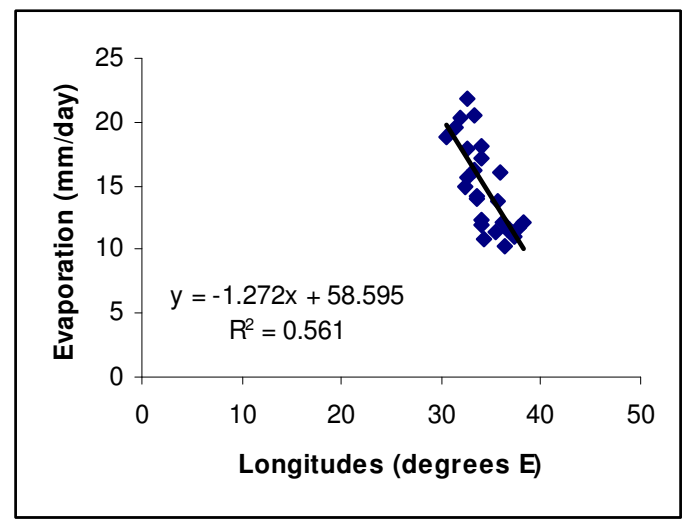

Figure 5: Piche evaporation vs. longitudes for the 27 stations

When the analysis was made for the 32 stations in Sudan and as can be seen in fig.6 two distinct trends appeared again; a western Sudan evaporation pattern with a slope of $-0.51 \mathrm{~mm} /$ degree east and a general a steep slope trend of $1.2 \mathrm{~mm} /$ degree east. The east ward decrease of evaporation is a manifestation of a higher humidity in the atmosphere because of water bodies represented by the Red Sea and possibly the Indian Ocean. However each of these strong correlations was limited to rather narrow ranges of longitudes, particularly the general trend.

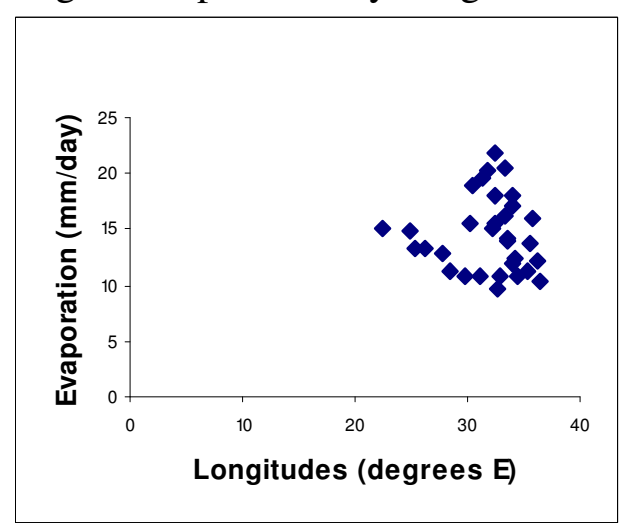

Figure 6: Piche evaporation vs. longitudes for 32 stations

\section{Evaporation and altitudes}

Evaporation showed no clear correlation with altitudes (Al) for the 42 stations together. However, when the 5 RS and 5 SS stations were removed from the scatter, the correlation became significant ( $\mathrm{P}=0.01)$, but with rather low $\mathrm{R}(0.43)$ and high SE (3.0). Although higher elevation means lower temperature, the week correlation is a reflection of the relative weights of the various factors involved in the process of evaporation.

\section{Evaporation vs. two and three factors}

The following tables show some parameters of linear regression between Piche evaporation (PE) and both, latitudes and longitudes, and evaporation and all the three factors. The strongest correlations, the highest significances and the lowest standard errors were obtained for the whole area (37 stations), but without the 5 RS stations. The best equations for prediction of Piche evaporation were therefore no. 3, 6 and 1 representing the 37 stations. Although equation 3 is the best regarding the parameters of correlation, equation (1) is easier to handle. 
Table 2: Effects of both latitudes (La.) and longitudes (Lon.) on evaporation

\begin{tabular}{ccccc}
\hline No. of stations & $\mathrm{R}$ & $\mathrm{P}$ & Equation & Eq no. \\
\hline 42 & 0.77 & $1.96 E-08$ & $\mathrm{PE}=14.40+0.86$ La. -0.42 Lon.......(2) \\
37 & 0.91 & $3.1 E-14$ & $\mathrm{PE}=06.21+$ 1.05La.-0.23Lon.......(3) \\
32 & 0.87 & $7.07 E-10$ & $\mathrm{PE}=07.94+1.06$ La.-0.28Lon......(4) \\
\hline
\end{tabular}

$E$ is the exponent to base 10

Table 3 Effect of the three factors on Evaporation

\begin{tabular}{lccc}
\hline No. of stations & $\mathrm{R}$ & $\mathrm{P}$ & Equation \\
\hline 42 & 0.80 & $1.42 E-08$ & $\mathrm{PE}=6.13+0.96 \mathrm{La}-0.28$ Lon $+0.005 \mathrm{Al} \ldots \ldots \ldots(5)$ \\
37 & 0.91 & $2.68 E-13$ & $\mathrm{PE}=7.86+1.04$ La-0.25Lon-0.001Al........ \\
32 & 0.87 & $3.83 E-09$ & $\mathrm{PE}=10.83+1.01$ La.-0.32Lon. $-0.002 \mathrm{Al} \ldots \ldots .(7)$ \\
\hline E is the exponent to base 10 &
\end{tabular}

Evaporation Variations between Stations and Between Months

Analysis of monthly normal Piche evaporation for the period 1961-1990 for the whole 42 stations showed that average daily evaporation varied between months from a minimum of $10.3 \mathrm{~mm} / \mathrm{day}$ in August to a maximum of $17.2 \mathrm{~mm} /$ day in April. It also showed that the average yearly evaporation varied between stations from a minimum of $5.7 \mathrm{~mm} /$ day in Rumbek, (latitude $6.8 \mathrm{~N}$ ) to a maximum of $21.7 \mathrm{~mm} /$ day in No.6, (latitude 20.75 $\mathrm{N})$.There were highly significant differences in the average daily Piche evaporation between stations ( $\mathrm{P}=9.1 \mathrm{E}-$ 53).There were also highly significant differences in the average daily Piche evaporation between months ( $\mathrm{P}=1.1 \mathrm{E}-26)$. These results were consistent with the fact that in August the Inter Tropical Convergence Zone is at its northern most position and the whole of the Sudan is almost under the influence of the moisture laden southern winds and receives varying amounts of rainfall (Mohamed,1998). This leads to low temperature and low evaporation. April, on the other hand, is one of the hottest months in Sudan and it is generally a dry month and on average it gave the highest evaporation rate. Likewise, evaporation is lowest in Rumbek because it ${ }^{\mathrm{s}}$ climate is more humid while
No.6 receives almost no rainfall (Mohamed, 2013).

\section{Conclusions}

This study showed that Piche evaporation over Sudan and SS and with the exception of the RS area varies substantially with latitudes and can be estimated to a good approximation with a simple equation that works particularly well along the western and central part of the country. The study also showed that Piche evaporation varies with longitude, but in a more localized manner according to the prevailing topography. The interaction of both latitudes and longitudes produced the best predicting equation shown as no. (3). These equations will be of use in areas where no evaporation measurements are available with the exception of RS coastal and nearby areas approximately between longitudes 36 and 38 degrees east. Altitudes seem to have no pronounced effects on evaporation compared to latitudes and longitudes.

\section{References}

Diskin, M.H. (1970). Factors affecting variations of mean annual rainfall in Israel. Bulletin of the International Association of the Scientific Hydrology, 15(4): 41-49

Fayed, Y.A.M. (1966). The climate of the Sudan according to three climatic classifications. Bulletin de la 
societede geographie D' Egypte, Tome $\mathrm{xxx} 1 \mathrm{x}$.

Gasm El Seed, A.M. (1968). Some aspects of measured and estimated evaporation in the Sudan. MSC. Theses submitted to Durham University, 1968.

Mohamed, H. A. (1998). Rainfall in Sudan: Trends and Agricultural implications. Sudan J. of Agric. Research, V(1):45-48.

Mohamed, H. A. (2012). A simple Thermal zonation of Sudan. Sudan J. of Des. Res. 4(1):1-15

Mohamed, H. A. (2013). Sudan Rainfall Trends: A Reversible Drop or a part of a Persistent Climate Change. Sudan J. Des. Res. 5(1): 62-74.

Nicholls, N. and Wong, K.K. (1990). Dependence of rainfall variability on mean rainfall, latitude and the southern oscillation. Journal of Climate 3:163-170.

Oliver, J. (1965). Evaporation losses and rainfall regime in central and north Sudan. Weather, 20(2):58-64.

Ireland, A.W. (1948). The climate of the Sudan. In: Agriculture in the Sudan.
Edited by J. D. Tothill, 1948. London: Oxford University Press. pp. 62-83.

Pasternak, L., Woltering, J. and Ndjeunga, S.P. (2010). Innovative and sustainable approaches for agricultural water management in the dry lands of the developing world.http://www.actahort.org/books/ 922/922 $15 . \mathrm{htm}$

Shaltout, M.A.M. and El Housry, T. (1997). Estimating the evaporation over Nasser lake in the upper Egypt from Meteosat observations. Advanced Space Research, 19(3):515-518

Trajkovic, S. and Gocic, M. (2010). Comparison of some empirical equations for estimating daily reference evapotranspiration. FACTA UNIVERSITATIS, series: Architecture and Civil Engineering, 8(2): 163-168.

$\mathrm{Xu}, \mathrm{C}-\mathrm{Y}$ and Singh, V.P. (2001). Evaluation and generalization of temperature- based methods for calculating evaporation. Hydrol. Process, 305-319. 